\title{
Universality of interpersonal psychotherapy (IPT) problem areas in Thai depressed patients
}

\author{
Peeraphon Lueboonthavatchai, Nuntika Thavichachart
}

\begin{abstract}
Background: Many studies have shown the efficacy of interpersonal psychotherapy (IPT) on depression; however, there are limited studies concerning the universality of the IPT problem areas in different countries. This study identifies whether the interpersonal problem areas defined in the IPT manual are endorsed by Thai depressed patients.

Methods: The Thai Hamilton Rating Scale for Depression (Thai HRSD) and Thai Interpersonal Questionnaire were used to assess 90 depressed and 90 non-depressed subjects in King Chulalongkorn Memorial Hospital, during July 2007 - January 2008. The association between interpersonal problem areas/sociodemographic variables and depressive disorder were analyzed by chi-square test. A multivariable analysis was performed by using logistic regression to identify the remaining factors associated with depressive disorder.

Results: Most of the subjects were young to middle-aged females living in Bangkok and the Central Provinces. All four interpersonal problem areas (grief, interpersonal role disputes, role transitions, and interpersonal deficits) were increased in the depressed subjects as compared to the non-depressed subjects, as were the sociodemographic variables (low education, unemployment, low income, and having a physical illness). Logistic regression showed that all interpersonal problem areas still remained problems associated with depression (grief: adjusted $\mathrm{OR}=6.01$, $95 \% \mathrm{Cl}=1.93-18.69, \mathrm{p}<0.01$; interpersonal role disputes: adjusted $\mathrm{OR}=6.01,95 \% \mathrm{Cl}=2.18-16.52, \mathrm{p}<0.01$; role transitions: adjusted $\mathrm{OR}=26.30,95 \% \mathrm{Cl}=7.84-88.25, \mathrm{p}<0.01$; and interpersonal deficits: adjusted $\mathrm{OR}=2.92,95 \%$ $\mathrm{Cl}=1.12-7.60, \mathrm{p}<0.05)$.
\end{abstract}

Conclusion: All four interpersonal problem areas were applicable to Thai depressed patients.

\section{Background}

Depressive disorder was one of the leading causes of worldwide disease burden, accounting for $4.46 \%$ of total disability-adjusted life-years (DALYs), and for $12.1 \%$ of total years lived with disabilities (YLDs) in 2000 [1]. Both major depressive disorder and dysthymic disorder are common depressive disorders, with a lifetime prevalence of about $15 \%$ and $3-6 \%$ respectively $[2,3]$. In Thailand, the lifetime prevalence of depressive disorder is about $5.7-20.9 \%$ [4]. Depressive disorder is believed to be caused by both biological and psychosocial factors.

Interpersonal psychotherapy (IPT), developed by Klerman and Weissman and based on the interpersonal theory of Adolf Meyer and Harry Stack Sullivan, has defined four interpersonal problem areas

\footnotetext{
* Correspondence: peeraphon_tu@yahoo.com
Department of Psychiatry, Faculty of Medicine, Chulalongkorn University,

* Correspondence: peeraphon_tu@yahoo.com Bangkok, Thailand
} Bangk, Thailand

associated with the onset of a depressive episode [5-9]. The problem areas are: 1) grief or complicated bereavement, 2) interpersonal role disputes, 3) role transitions, and 4) interpersonal deficits [7-9]. IPT is thought to relieve depressive symptoms by helping patients resolve their interpersonal difficulties. IPT is a manualized form of psychotherapy and one of the evidence-based psychotherapies (EBTs) of depression [10-14]. Based on previous studies, IPT showed efficacy on treatment of depressive disorder and other psychiatric disorders [15-17]. However, there are still limited studies on the validity of interpersonal problem areas and whether they can be translated across cultures.

Previous studies focused on adverse life events related to depression. Holmes and Rahe reported that the most stressful life event was the death of a spouse [18]. Other important stressful life events included divorce, marital separation, detention in jail, death of a close family 
member, and major injury or illness [18]. Kendler reported that the stressful life events predicting the onset of major depression included death of a close relative, assault, serious marital problems, and divorce or breakup (odds ratio of more than 10) [19]. Markowitz found a correlation between interpersonal problem improvement and reduction of depressive symptoms in 24 patients $[20,21]$.

Interpersonal difficulties, such as grief, interpersonal conflicts, life transitions, and social isolation seem to be universal human experiences; however, they may differ between cultures due to different socio-cultural experience. For example, Verdeli and Clougherty found that the fourth interpersonal problem area, interpersonal deficits, was not recognized as a problem area in Uganda because people in Uganda lived in tight-knit social groups and were never alone [22].

This study is aimed at identifying the interpersonal problem areas as defined in the IPT manual in Thai depressed patients. Studying interpersonal problems of Thai patients will help to determine whether these problems are present and an appropriate target of treatment, and will guide the adaptation of IPT for use in Thailand.

\section{Methods}

Ninety depressed and ninety non-depressed subjects above 18 years old were recruited from the Department of Psychiatry, King Chulalongkorn Memorial Hospital in Bangkok during July 2007 - January 2008. Approval for the study was obtained from the Ethical Committee of the Institutional Review Board of the Faculty of Medicine, Chulalongkorn University. All 90 potential depressed subjects were consecutive patients who met the eligibility criteria during the period of study and were informed of the study's objectives and method. They voluntarily participated in the study and gave written informed consent. The inclusion criteria for the depressed subjects (cases) were that they were new cases (within 6 months) of major depressive disorder being diagnosed using the Diagnostic and Statistical Manual of Mental Disorders, $4^{\text {th }}$ edition, Text Revision (DSM-IVTR) criteria [23], and that they had scores of at least 8 points on the Thai Hamilton Rating Scale for Depression (Thai HRSD) [24]. The exclusion criteria were schizophrenia and other psychotic disorders, bipolar disorders, organic mental disorders, substance use disorders, and mental retardation. The 90 non-depressed subjects or controls were recruited through the Department of Psychiatry and from family members or caregivers of psychiatric patients who were determined to have no depressive or other psychiatric disorders by psychiatric interview and had scores of less than 8 points on the Thai HRSD in the same period. All subjects completed two self-administered questionnaires: 1) the Demographic Data Form, and 2) the Thai Interpersonal Questionnaire.

The Thai HRSD is the Thai version of the Hamilton Rating Scale for Depression (HAM-D), the psychiatric rating scale widely used for evaluation of depressive disorder [25]. It was tested and found to have good validity and reliability in measuring the severity of depression in Thai depressed patients [24] (Cronbach's alpha coefficient $=0.74$ ). The Thai HRSD is composed of 18 items and had a range of total scores from 0 to 57 . The scores of 7 or under indicate an absence of depression; scores of 8 to 29 represent mild to major depression; and scores of 30 or above indicate severe depression or psychotic symptoms.

The Thai Interpersonal Questionnaire was developed for identifying interpersonal problem areas described in IPT and was adapted from the IPT manual [7]. The questionnaire is composed of four groups of items for identifying interpersonal problem areas: 1 ) grief or complicated bereavement (scores: 0 - 12), 2) interpersonal role disputes $(0-15), 3)$ role transitions $(0-9)$, and 4$)$ interpersonal deficits $(0-12)$. This questionnaire showed good validity and reliability (Cronbach's alpha coefficient for grief $=0.79$; interpersonal role disputes $=$ 0.96 ; role transitions $=0.96$; and interpersonal deficits $=$ 0.82). A high score on each subscale of an interpersonal problem area indicates a problem in adjusting in that area. The total range of scores for each problem area was divided into 3 intervals. The scores indicating the subjects' problem areas were the scores above the second interval that were compatible with the problem areas diagnosed by the clinical interview.

A statistical analysis was performed by using STATA for Windows version 8.0 software. The baseline demographic characteristics of the depressed (cases) and the non-depressed subjects (controls) were presented in number and percentage. The chi-square test was used to test the association between interpersonal problem areas/sociodemographic factors and depressive disorder. The strength of association between interpersonal problem areas/sociodemographic factors and depressive disorder was reported by using odds ratio (OR) with $95 \%$ confidence interval $(95 \% \mathrm{CI})$. A multivariable analysis was performed by using logistic regression to identify the remaining factors associated with depressive disorder. A p-value of less than 0.05 was considered statistically significant.

\section{Results}

One hundred eighty subjects participated in the study: 90 depressed and 90 non-depressed subjects (Table 1). Most of them were female $(78.9 \%)$ and in the age range of $31-70$ years (mean age $=42.8, \mathrm{SD}=12.0$ ). About 
Table 1 Demographic characteristics of the depressed (n $=90)$ and the non-depressed $(n=90)$ subjects

\begin{tabular}{|c|c|c|c|}
\hline $\begin{array}{l}\text { Demographic } \\
\text { characteristics }\end{array}$ & $\begin{array}{l}\text { Depressed } \\
(\mathrm{n}=90) \\
\mathrm{N}, \text { percent }\end{array}$ & $\begin{array}{l}\text { Non- } \\
\text { depressed } \\
(n=90) \\
N, \text { percent }\end{array}$ & $\begin{array}{l}\text { Total } \\
(n=180) \\
N \text {, percent }\end{array}$ \\
\hline \multicolumn{4}{|l|}{ Gender } \\
\hline Female & $71,78.9 \%$ & $71,78.9 \%$ & $142,78.9 \%$ \\
\hline Male & $19,21.1 \%$ & $19,21.1 \%$ & $38,21.1 \%$ \\
\hline \multicolumn{4}{|l|}{ Age } \\
\hline 18 - 30 years & $16,17.8 \%$ & $16,17.8 \%$ & $32,17.8 \%$ \\
\hline 31 - 40 years & $17,18.9 \%$ & $21,23.3 \%$ & $38,21.1 \%$ \\
\hline $41-50$ years & $32,35.6 \%$ & $26,28.9 \%$ & $58,32.2 \%$ \\
\hline 51 - 70 years & $25,27.8 \%$ & $27,30.0 \%$ & $52,28.9 \%$ \\
\hline Mean \pm SD & $42.7 \pm 11.9$ & $43.0 \pm 12.1$ & $42.8 \pm 12.0$ \\
\hline Min, Max & 18,66 & 18,68 & 18,68 \\
\hline \multicolumn{4}{|l|}{ Marital status } \\
\hline Couple & $59,65.6 \%$ & $52,57.8 \%$ & $111,61.7 \%$ \\
\hline Others & $31,34.4 \%$ & $38,42.2 \%$ & $69,38.3 \%$ \\
\hline \multicolumn{4}{|l|}{ Educational level } \\
\hline $\begin{array}{l}\text { Secondary school and } \\
\text { lower }\end{array}$ & $52,57.8 \%$ & $35,38.9 \%$ & $87,48.3 \%$ \\
\hline $\begin{array}{l}\text { Bachelor's degree and } \\
\text { higher }\end{array}$ & $38,42.2 \%$ & $55,61.1 \%$ & $93,51.7 \%$ \\
\hline \multicolumn{4}{|l|}{ Occupation } \\
\hline Employed & $51,56.7 \%$ & $74,82.2 \%$ & $125,69.4 \%$ \\
\hline Unemployed & $39,43.3 \%$ & $16,17.8 \%$ & $55,30.6 \%$ \\
\hline \multicolumn{4}{|l|}{ Incomes (baht/month) } \\
\hline Lower than 10,000 & $56,62.2 \%$ & $38,42.2 \%$ & $94,52.2 \%$ \\
\hline 10,000 and above & $34,37.8 \%$ & $52,57.8 \%$ & $86,47.8 \%$ \\
\hline \multicolumn{4}{|l|}{ Having a physical illness } \\
\hline Presence & $43,47.8 \%$ & $28,31.1 \%$ & $71,39.4 \%$ \\
\hline Absence & $47,52.2 \%$ & $62,68.9 \%$ & $109,60.6 \%$ \\
\hline \multicolumn{4}{|l|}{ Residence } \\
\hline $\begin{array}{l}\text { Bangkok and Central } \\
\text { Provinces }\end{array}$ & $78,86.7 \%$ & $85,94.4 \%$ & $163,90.6 \%$ \\
\hline Others & $12,13.3 \%$ & $5,5.6 \%$ & $17,9.4 \%$ \\
\hline
\end{tabular}

$62 \%$ were married, $33.3 \%$ were single, and $5 \%$ were separated, widowed, or divorced. About half had a bachelor's degree education or above. Nearly $70 \%$ of subjects were employed. Nearly half of the subjects had an income of 10,000 baht per month or above. Thirty-nine percent had at least one physical illness. Most (90\%) lived in Bangkok and the Central Provinces (Table 1).

The scores on the Thai HRSD and Thai Interpersonal Questionnaire of the depressed and the non-depressed subjects are shown in Table 2. The scores of Thai HRSD, which indicate the severity of depression, varied from 0 - 43 (the depressed: 8 - 43 vs. the non-depressed: 0 - 7). The mean Thai HRSD score of total subjects was 14.32 (the depressed: $25.34 \pm 8.58$ vs. the non-depressed: $3.29 \pm 2.67)$. The scores of all interpersonal problem
Table 2 Scores on Thai HRSD and Thai Interpersonal Questionnaire of the depressed $(n=90)$ and the nondepressed $(\mathbf{n}=90)$ subjects

\begin{tabular}{|c|c|c|c|}
\hline Scores & $\begin{array}{l}\text { Depressed } \\
(n=90) \\
\text { Mean, SD }\end{array}$ & $\begin{array}{l}\text { Non- } \\
\text { depressed } \\
(n=90) \\
\text { Mean, SD }\end{array}$ & $\begin{array}{l}\text { Total } \\
(n=180) \\
\text { Mean, SD }\end{array}$ \\
\hline Thai HRSD (0 - 52) & $25.34,8.58$ & $3.29,2.67$ & $\begin{array}{l}14.32 \\
12.75\end{array}$ \\
\hline (Min, Max) & $(8,43)$ & $(0,7)$ & $(0,43)$ \\
\hline \multicolumn{4}{|l|}{$\begin{array}{l}\text { Thai Interpersonal } \\
\text { Questionnaire }\end{array}$} \\
\hline Grief $(0-12)$ & $2.87,3.61$ & $0.88,1.53$ & $1.87,2.93$ \\
\hline (Min, Max) & $(0,10)$ & $(0,6)$ & $(0,10)$ \\
\hline $\begin{array}{l}\text { Interpersonal role disputes } \\
(0-15)\end{array}$ & $7.61,4.80$ & $3.42,4.14$ & $5.52,4.94$ \\
\hline (Min, Max) & $(0,15)$ & $(0,14)$ & $(0,15)$ \\
\hline Role transitions (0 - 9) & $4.56,3.19$ & $0.54,1.40$ & $2.56,3.18$ \\
\hline (Min, Max) & $(0,9)$ & $(0,7)$ & $(0,9)$ \\
\hline Interpersonal deficits $(0-12)$ & $4.20,3.01$ & $1.56,1.97$ & $2.68,2.96$ \\
\hline (Min, Max) & $(0,11)$ & $(0,7)$ & $(0,11)$ \\
\hline
\end{tabular}

areas in the depressed subjects were higher than the non-depressed subjects (Table 2).

The relationship between interpersonal problem areas/ sociodemographic variables and depressive disorder is shown in Table 3. All interpersonal problem areas were associated with depressive disorder (grief: $\mathrm{OR}=4.79$, $95 \% \mathrm{CI}=2.14-11.29, \mathrm{p}<0.01$; interpersonal role disputes: $\mathrm{OR}=4.80,95 \% \mathrm{CI}=2.42-9.56, \mathrm{p}<0.01$; role transitions: $\mathrm{OR}=31.00,95 \% \mathrm{CI}=11.50-94.99, \mathrm{p}<$ 0.01; and interpersonal deficits: $\mathrm{OR}=7.42,95 \% \mathrm{CI}=$ $3.58-15.60, \mathrm{p}<0.01)$. In the problem area of role transitions, the common life changes that the subjects reported included separation and divorce, a move, job loss, health problems or physical illness, and financial problems. Among sociodemographic variables, the factors associated with depressive disorder included low education $(\mathrm{OR}=2.15,95 \% \mathrm{CI}=1.14-4.08, \mathrm{p}<0.05)$, unemployment $(\mathrm{OR}=4.58,95 \% \mathrm{CI}=2.32-9.11, \mathrm{p}<$ $0.01)$, low income $(\mathrm{OR}=2.25,95 \% \mathrm{CI}=1.19-4.28, \mathrm{p}<$ 0.05 , and having a physical illness: $\mathrm{OR}=2.03,95 \% \mathrm{CI}=$ $1.06-3.90, \mathrm{p}<0.05)$.

The multivariable analysis showed that the remaining factors associated with depressive disorder were four interpersonal problem areas: grief (adjusted $\mathrm{OR}=6.01$, $95 \% \mathrm{CI}=1.93-18.69, \mathrm{p}<0.01)$, interpersonal role disputes (adjusted $\mathrm{OR}=6.01,95 \% \mathrm{CI}=2.18-16.52, \mathrm{p}<$ 0.01 ), role transitions (adjusted $\mathrm{OR}=26.30,95 \% \mathrm{CI}=$ 7.84 - 88.25, $\mathrm{p}<0.01$ ), and interpersonal deficits (adjusted OR $=2.92,95 \% \mathrm{CI}=1.12-7.60, \mathrm{p}<0.05)$. The sociodemographic factors (low education, unemployment, and having a physical illness) were not found to be associated with depressive disorder (Table 4). 
Table 3 Relationship between interpersonal problem areas/sociodemographic factors and depressive disorder in the depressed $(n=90)$ and the non-depressed $(n=90)$ subjects

\begin{tabular}{|c|c|c|c|c|c|c|c|}
\hline \multirow[t]{2}{*}{$\begin{array}{l}\text { Interpersonal problem areas and } \\
\text { sociodemographic factors }\end{array}$} & & $\begin{array}{l}\text { Numbers } \\
(n=180)\end{array}$ & & Odds ratio (OR) & $\begin{array}{l}95 \% \mathrm{Cl} \\
\text { Of OR }\end{array}$ & $x^{2}$ & $p$-value \\
\hline & $\begin{array}{l}\text { Depressed } \\
(90)\end{array}$ & $\begin{array}{c}\text { Non-depressed } \\
(90)\end{array}$ & $\begin{array}{l}\text { Total } \\
(180)\end{array}$ & & & & \\
\hline
\end{tabular}

Interpersonal problem areas

Grief

\begin{tabular}{|c|c|c|c|c|c|c|}
\hline Exposed & 36 & 11 & 47 & 4.79 & $2.14-11.29$ & $<0.0001^{* *}$ \\
\hline Unexposed & 54 & 79 & 133 & & & \\
\hline Total & 90 & 90 & 180 & & & \\
\hline
\end{tabular}

Interpersonal role disputes

$\begin{array}{lllcccc}\text { Exposed } & 67 & 34 & 101 & 4.80 & 2.42-9.56 & 24.57<0.0001^{* *} \\ \text { Unexposed } & 23 & 56 & 79 & & & \\ \text { Total } & 90 & 90 & 180 & & \end{array}$

Role transitions

Exposed

Unexposed

Total

$\begin{array}{llc}62 & 6 & 68 \\ 28 & 84 & 112 \\ 90 & 90 & 180\end{array}$

Interpersonal deficits

Exposed
Unexposed
Total

Sociodemographic factors

\section{Educational level}

Secondary school and lower

Bachelor's degree and higher

Total

$\begin{array}{ccc}52 & 35 & 87 \\ 38 & 55 & 93 \\ 90 & 90 & 180\end{array}$

Occupation

Unemployed
Employed
Total

Incomes (baht/month)

Lower than 10,000

10,000 and above

Total

$\begin{array}{llc}55 & 23 & 78 \\ 35 & 67 & 102 \\ 90 & 90 & 180\end{array}$

4.58

$2.32-9.11$

$23.17<0.0001^{* *}$

102

2.15

$1.14-4.08$

6.43

$0.01^{*}$

80 
Table 4 Multivariable analysis of factors associated to depressive disorder in Thai depressed patients

\begin{tabular}{|c|c|c|c|c|}
\hline Variables & Coefficient ( $\beta$ ) & p-value & $\begin{array}{l}\text { Adjusted odds } \\
\text { ratio (OR) }\end{array}$ & $\begin{array}{l}95 \% \mathrm{Cl} \text { of } \\
\text { adjusted } \mathrm{OR}\end{array}$ \\
\hline \multicolumn{5}{|l|}{ Interpersonal problem areas } \\
\hline - Grief & 1.793 & $0.002^{* *}$ & 6.01 & $1.93-18.69$ \\
\hline - Interpersonal role disputes & 1.793 & $0.001^{* *}$ & 6.01 & $2.18-16.52$ \\
\hline - Role transitions & 3.270 & $<0.001^{* *}$ & 26.30 & $7.84-88.25$ \\
\hline - Interpersonal deficits & 1.070 & $0.029^{*}$ & 2.92 & $1.12-7.60$ \\
\hline \multicolumn{5}{|l|}{ Sociodemographic factors } \\
\hline - Low education & 0.775 & 0.117 & 2.17 & $0.82-5.72$ \\
\hline - Unemployment & 0.786 & 0.112 & 2.19 & $0.83-5.78$ \\
\hline - Having a physical illness & -0.507 & 0.346 & 0.60 & $0.21-1.73$ \\
\hline
\end{tabular}

${ }^{*} p<0.05,{ }^{* *} p<0.01$.

interpersonal role disputes, role transitions, and interpersonal deficits $(\mathrm{p}<0.01)$; and certain sociodemographic factors: low education, unemployment, low income, and having a physical illness $(\mathrm{p}<0.05)$. After performing a multivariable analysis, only the four interpersonal problem areas: grief, interpersonal role disputes, role transitions $(\mathrm{p}<0.01)$, and interpersonal deficits $(\mathrm{p}<0.05)$ remained. This indicates that the problem areas are more closely associated with depressive disorder than the sociodemographic variables.

Among interpersonal problem areas, role transitions had the strongest association with depressive disorder (adjusted OR $=26.30,95 \% \mathrm{CI}=7.84-88.25, \mathrm{p}<0.01$ ). The subjects in this study were in young to middle-aged adulthood; therefore, life changes were important issues in this stage [26]. Many people reported unsatisfactory experiences when having to adjust to major life changes such as separation or divorce, job loss, physical illness, and financial problems. Difficulties in adjusting to a new role may be due to loss of social support from the old role, feeling uncomfortable with the new role, or perceiving the new role as overwhelming or anxiety-provoking [8]. Previous research determined that widowhood promotes anxiety and depression by increasing concerns about living alone and loneliness [27], job loss heightened a two- to three-fold rate of anxiety and depression by increasing financial strain and heightening reactivity to stress $[27,28]$. Previous studies in Thai depressed patients showed that the adverse life events associated with depression were major health problems, financial problems, job loss, separation or divorce, and being unable to adjust to life change $[29,30]$.

Grief or complicated bereavement, especially spousal bereavement, is the most stressful life event precipitating depression $[18,19]$. One study determined that annually in the US, approximately 800,000 people were newly widowed and bereaved [31]. Bereavement was found to lead to chronic depression in approximately $10-15 \%$ of cases and depressive disorder was found in $24-42 \%$ of the bereaved at 1 month, $16 \%$ at 1 year, but was found in only $8 \%$ of the non-bereaved [32-35]. In a previous study in Thailand, the death of a loved one was associated with depression as well [29]. In the present study, grief was found as an interpersonal problem area related to depression, but this problem area did not show the highest strength of association among other problem areas (adjusted OR $=6.01,95 \% \mathrm{CI}=1.93-18.69, \mathrm{p}<0.01$ ). This may be due to the relatively young age of the samples.

Interpersonal role disputes is another interpersonal problem area associated with depressive disorder in this study (adjusted OR $=6.01,95 \% \mathrm{CI}=2.18-16.52, \mathrm{p}<$ $0.01)$. Interpersonal role disputes include arguments or disagreements with a spouse (marital conflicts), family member, boss, colleague or co-worker, or a close friend [7-9]. Although interpersonal disputes are common, they may become a problem when they can not be resolved or remain chronic [8], leading to frustration, anger, and despair. Depressed patients with disputes tend to have maladaptive communication patterns such as ambiguous or indirect verbal and nonverbal communication, low assertiveness, an incorrect assumption that others understood their opinions or their needs, or closing off communication or being silent [7-9]. Previous studies showed that depressed patients had more problematic interpersonal relationships with their spouses and families than the non-depressed individuals [36-39]. Regarding the quality of interaction, the depressed individuals had significantly fewer positive interactions and more negative interactions with their spouses or partners than non-depressed ones [40]. A study in Thailand found depressed women to have significantly higher interpersonal conflicts than non-depressed women [41].

Interpersonal deficits were also found as an interpersonal problem area related to depressive disorder, but in the weakest association (adjusted OR $=2.92,95 \% \mathrm{CI}=$ $1.12-7.60, \mathrm{p}<0.05)$. Interpersonal deficits include lack of interpersonal or social skills and lack of social support [7-9]. Some indicators for interpersonal deficits 
include limited friends or family contact, lack of socially rewarding relationships, and repeated relationship failures [8]. People with interpersonal deficits usually have difficulty in life adjustment when experiencing interpersonal crises such as grief, or role transitions because they have difficulty in developing social connections with others after life changes [8]. Previous studies confirmed that poor social support was related to the onset, relapse, and recurrence of depressive disorder [36]. In Thailand, poor social support was associated with the depressive disorder in Thai women [41]. In the present study, interpersonal deficits were shown to have the weakest association with depressive disorder in Thai depressed patients. This may relate to the Thai sociocultural system and Thai family structure. Thai people, as compared to Westerners, have large extended families and close connections to their families and relatives. The results of the present study suggest that interpersonal deficits are less relevant and can be disregarded as an IPT focus in Thailand. IPT was first developed in the treatment of white middle-class women in the Boston area of the United States of America. The present study addresses the universality and applicability of IPT in Thailand. In Thailand, people's character and culture differ from those of Western countries. Thais' manners and culture extend mainly from farming and Buddhism. The lifestyle of Thais is simple, easy, and generous. Thai people like to live together in cooperation and tend to have large extended families composed of grandparents, parents, sons or daughters, and grandchildren. In this culture, younger generations are taught to respect their elders and to be grateful to their parents and older relatives by taking care of them. However, compared to Westerners, Thais are more dependent and may be less assertive. When aiming to improve communication in Thai depressed patients, IPT therapists should work within the framework of the Thai lifestyle and culture.

As discussed above, although the socio-cultural context in Thailand is different from the West, the same interpersonal difficulties are endorsed by Thai depressed patients, but vary in degree.

This study attempted to reduce confounding factors by using the same-based controls from the hospital. However, the findings should be interpreted in the context of depressed patients in a clinical setting. These factors may have influenced the interpersonal problem areas that they experienced. In addition, this study is an analytic or case-control study trying to identify the interpersonal or social risks of depressive disorder in Thai depressed patients. However, tracing back the history of experiencing interpersonal events over the past year may result in recall bias in the subjects. Further prospective or cohort studies may help to identify more causal effects of these risks on depressive disorder.

\section{Conclusion}

The study of universality of interpersonal problem areas in Thai depressed patients showed that grief, interpersonal role disputes, role transitions, and interpersonal deficits were all increased in depressed subjects as compared to non-depressed subjects, with role transitions having the strongest association with depressive disorder and interpersonal deficits the weakest. This finding makes interpersonal psychotherapy, which deals with these interpersonal difficulties, a suitable treatment for Thai depressed patients.

\section{Acknowledgements}

This study was supported by the Ratchadapiseksompotch Fund, Faculty of Medicine, Chulalongkorn University, Bangkok, Thailand. The authors also wish to thank Myrna M. Weissman, Ph.D. and Helena Verdeli, Ph.D. for the use of the Interpersonal Questionnaire Baseline, and Manote Lotrakul, M.D. and his colleagues for the use of the Thai HRSD; Myrna M. Weissman, Ph.D. for valuable suggestions and comments on this study; Marc B.J. Blom, M.D. and Nickolai Titov, Ph.D. for the valuable suggestions for revision of the manuscript.

\section{Authors' contributions}

PL was the principal investigator for the study (conception and design of the study, literature review, protocol preparation, conducting the study, data collection, data analysis, interpretation of the results, and manuscript preparation and revision). NT contributed to the conception and design, interpretation of the results, revision and approval of the manuscript.

\section{Competing interests}

Dr. Lueboonthavatchai and Dr. Thavichachart are both affiliated with the Department of Psychiatry, Faculty of Medicine, Chulalongkorn University, Rama 4 Road, Patumwan District, Bangkok 10330, Thailand. The authors both declare that they have no financial or non-financial competing interests.

Received: 3 February 2010 Accepted: 21 October 2010

Published: 21 October 2010

\section{References}

1. Ustun TB, Ayuso-Mateos JL, Chatterji S, Mathers C, Murray CJL: Global burden of depressive disorders in the year 2000. Br J Psychiatry 2004, 184:386-92.

2. Sadock BJ, Sadock VA: Synopsis of psychiatry: behavioral sciences/clinical psychiatry. Lippincott: Williams \& Wilkins, 102007.

3. Sadock BJ, Sadock VA: Synopsis of psychiatry: behavioral sciences/clinical psychiatry. Baltimore: Williams \& Wilkins, 92003.

4. Thavichachart N, Intoh P, Thavichachart T, Meksupa O, Tangwongchai S, Sughondhabirom $A$, et al: Epidemiological survey of mental disorders and knowledge attitude practice upon mental health among people in Bangkok Metropolis. J Med Assoc Thai 2001, 84(Suppl 1):S118-26.

5. Meyer A: Psychobiology: a science of man. Springfield, III: Charles C. Thomas 1957.

6. Sullivan HS: The interpersonal theory of psychiatry. New York: W.W. Norton 1953.

7. Weissman MM, Markowitz JC, Klerman GL: Comprehensive guide to interpersonal psychotherapy. New York: Basic Books 2000.

8. Stuart S, Robertson M: Interpersonal psychotherapy: a clinician's guide. New York: Oxford University Press Inc 2003.

9. Lueboonthavatchai P: Interpersonal psychotherapy: a new option for treatment of depression. J Psychiatr Assoc Thailand 2006, 51(2):117-31.

10. Cuijpers P, van Straten A, Andersson G, van Oppen P: Psychotherapy for depression in adults: a meta-analysis of comparative outcome studies. $J$ Consult Clin Psychol 2008, 76(6):909-22.

11. Chambless D, Hollon S: Defining empirically supported therapies. J Consult Clin Psychol 1998, 66(1):7-18.

12. Weissman MM, Sanderson WC: Promises and problems in modern psychotherapy: the need for increased training in evidence-based 
treatments. In Modern psychiatry: challenges in educating health professionals to meet new needs. Edited by: Hager M. New York: Macy Foundation; 2003:132-65.

13. Weissman MM, Prusoff BA, DiMascio A, Neu C, Goklaney M, Klerman GL: The efficacy of drugs and psychotherapy in the treatment of acute depressive episodes. Am J Psychiatry 1979, 136(4B):555-8.

14. Lueboonthavatchai P: Interpersonal psychotherapy: A current evidencebased therapy of depression. In Rational management in medical practice: proceeding of the 47th Annual Scientific Meeting, Faculty of Medicine, Chulalongkorn University. Edited by: Kanchanatawan B, Hemrungrojn S, Roomruangwong C. Bangkok: Phabpim; 2006:109-19.

15. Weissman MM, Klerman GL, Prusoff BA, Sholomskas D, Padian N: Depressed outpatients: results one year after treatment with drugs and/or interpersonal psychotherapy. Arch Gen Psychiatry 1981, 38(1):51-5.

16. DiMascio A, Weissman MM, Prusoff BA, Neu C, Zwilling M, Klerman GL: Differential symptom reduction by drugs and psychotherapy in acute depression. Arch Gen Psychiatry 1979, 36(13):1450-6.

17. Elkin I, Shea MT, Watkins JT, Imber SD, Sotsky SM, Collins JF, et al: National Institute of Mental Health Treatment of Depression Collaborative Research Program: general effectiveness of treatments. Arch Gen Psychiatry 1989, 46(11):971-82.

18. Holmes TH, Rahe RH: The Social Readjustment Rating Scale. J Psychosom Res 1967, 11(2):213-8.

19. Kendler KS, Kessler RC, Walters EE, MacLean C, Neale MC, Heath AC, et al: Stressful life events, genetic liability, and the onset of an episode of major depression in women. Am J Psychiatry 1995, 152(6):833-42.

20. Markowitz JC, Bleiberg KL, Chrristos P, Levitan E: Solving interpersonal problems correlates with symptom improvement in interpersonal psychotherapy: preliminary findings. J Nerv Ment Dis 2006, 194(1):15-20.

21. Markowitz JC, Leon AC, Miller NL, Cherry S, Clougherty KF, Villalobos L: Rater agreement on interpersonal psychotherapy problem areas. J Psychother Pract Res 2000, 9(3):131-5.

22. Verdeli H, Clougherty K, Bolton P, Speelman L, Lincoln L, Bass J, et al: Adapting group interpersonal psychotherapy for a developing country: experience in rural Uganda. World Psychiatry 2003, 2(2):114-20.

23. American Psychiatric Association: Diagnostic and Statistical Manual of Mental Disorders. Text Revision. Washington, D.C.: American Psychiatric Association, 42000.

24. Lotrakul M, Sukanich P, Sukying C: The reliability and validity of Thai version of Hamilton Rating Scale for Depression. J Psychiatr Assoc Thailand 1996, 41(4):235-46.

25. Hamilton M: A rating scale for depression. I Neurol Neurosurg Psychiatry 1960, 23:56-62.

26. Lueboonthavatchai P: Developmental stages: adulthood. In Human behavior \& mental disorder. Edited by: Kanchanatawan B, Lueboonthavatchai P. Bangkok: Chulalongkorn University Press; , 2 2004:39-61.

27. Kessler CK: Sociology and psychiatry. In Kaplan \& Sadock's comprehensive textbook of psychiatry. Edited by: Sadock BJ, Sadock VA. Baltimore: Lippincott Williams , 8 2005:1:623-7.

28. Swan GE, Dame A, Carmelli D: Involuntary retirement, type A behavior, and current functioning in elderly men: 27 -year follow-up of the Western Collaborative Group Study. Psychol Aging 1991, 6(3):384-91.

29. Kongsuk T, Udomratn P, Arunpongpaisan S, Lotrakul M, Maneeton N, Sitthiruk $N$, et al: Association between stressful life events and the onset of major depressive disorder episode in patients from five university hospitals in Thailand, 2006. J Psychiatr Assoc Thailand 2008, 53(1):61-8.

30. Lueboonthavatchai P: Role of stress areas, stress severity, and stressful life events on the onset of depressive disorder: a case-control study. $J$ Med Assoc Thai 2009, 92(9):1240-9.

31. Hensley PL: Treatment of bereavement-related depression and traumatic grief. J Affect Disord 2006, 92(1):117-24.

32. Zisook S, Shuchter SR, Sledge PA: Diagnostic and treatment considerations in depression associated with late-life bereavement. In Diagnosis and treatment of depression in late life. Edited by: Schneider LS, Reynolds CF, Lebowitz BD, Friedhoff AJ. Washington DC: American Psychiatric Press; 1994:419-36.

33. Clayton PJ, Darvish HS: Course of depressive symptoms following the stress of bereavement. In Stress and mental disorder. Edited by: Barrett J, Rose RM, Klerman GL. New York: Raven Press; 1979:121-36.

34. Zisook S, Shuchter SR: Depression through the first year after the death of a spouse. Am J Psychiatry 1991, 148(10):1346-52.
35. Lueboonthavatchai P: Grief and interpersonal psychotherapy: principle and management. J Psychiatr Assoc Thailand 2007, 52(1):29-45.

36. Weissman MM, Paykel ES: The depressed women: a study of social relationships. Chicago: University of Chicago Press 1974.

37. Hammen C: Generation of stress in the course of unipolar depression. $J$ Abnorm Psychol 1991, 100(4):555-61.

38. Davila J, Hammen C, Burge D, Paley B, Daley SE: Poor interpersonal problem solving as a mechanism of stress generation in depression among adolescent women. J Abnorm Psychol 1995, 104(4):592-600.

39. Hammen C, Brennen PA: Interpersonal dysfunction in depressed women: impairments independent of depressive symptoms. J Affect Disord 2002, 72(2):145-56.

40. Zlotnick C, Kohn R, Keitner G, Della Grotta SA: The relationship between quality of interpersonal relationships and major depressive disorder: findings from the National Comorbidity Survey. J Affect Discord 2000, 59(3):205-15.

41. Sangon S: Predictors of depression in Thai women. Res Theory Nurs Pract 2004, 18(2-3):243-60

\section{Pre-publication history}

The pre-publication history for this paper can be accessed here: http://www.biomedcentral.com/1471-244X/10/87/prepub

doi:10.1186/1471-244X-10-87

Cite this article as: Lueboonthavatchai and Thavichachart: Universality of interpersonal psychotherapy (IPT) problem areas in Thai depressed patients. BMC Psychiatry 2010 10:87.

\section{Submit your next manuscript to BioMed Central and take full advantage of:}

- Convenient online submission

- Thorough peer review

- No space constraints or color figure charges

- Immediate publication on acceptance

- Inclusion in PubMed, CAS, Scopus and Google Scholar

- Research which is freely available for redistribution

Submit your manuscript at www.biomedcentral.com/submit
Biomed Central 